\title{
Internet Addiction and Acculturative Stress Among International College Students in the United States
}

\author{
Jiaqi Li \\ Wichita State University, USA \\ Xun Liu \\ University of South Carolina, USA
}

\begin{abstract}
While Internet use plays an increasingly important role in individuals' lives, many college students have found themselves totally unconsciously plunged into Internet addiction (IA). Guided by the acculturative stress theory, we examined the relationships between acculturative stress, gender, age, length of stay, and IA among international college students. Data were collected from 111 international undergraduate and graduate students studying in the United States. Hierarchical multiple regression analyses reported that acculturative stress and gender significantly predict IA among international college students. In this sample, neither age nor length of stay predicted IA. Our findings paint a picture of the potential influence of acculturative stress on IA. We offer suggestions for future research on Internet addiction and acculturative stress, particularly for international college students.
\end{abstract}

Keywords: acculturative stress, college counselor, international college students, Internet addiction

Over the past decades, Internet addiction (IA) has become a campus health issue that cannot be ignored in the United Stated and other countries in the world (Anderson, 2001; Cardak, 2013; Carlisle et al., 2016; Kandell, 2009). Estimates indicate that $71 \%$ of $18-24$ year olds would qualify as being addicted to the 
Internet, and prevalence rates of IA are as high as $8.2 \%$ in the general population (Gaille, 2017; Weinstein \& Lejoyeux, 2010). To date, IA on college campuses is a growing concern as more and more studies are revealing (Chai et al., 2012; Ostovar et al., 2016). Research has indicated that college students with IA are likely to experience depression (Ineme et al., 2017; Ostovar et al., 2016), anxiety (Ostovar et al., 2016), loneliness (Zeliha, 2019), and poor physical health such as vision problems and weight gain or loss (Gregory, 2019). Of college students, international students appear to be more at risk of IA because their acculturation experiences entail adjustment difficulties and stress, which are related to excessive Internet use (Chai et al., 2012; Hirai et al., 2015; Ye, 2005). Research has shown that acculturative stress may contribute to IA (Jin \& Berge, 2016; Ye, 2005). International students use the Internet as a means to cope with unpleasant feelings (e.g., perceived discrimination, cultural shock) during the process of acculturation (Ye, 2005). Despite the attention to IA, a limited number of studies on international students with IA have been reported. Given the prevalence and complexities of IA among international students, it is imperative to identify the factors implicated in IA so that counselors can more effectively target intervention to reduce the likelihood of IA. In the current study, we therefore examined the relationships between acculturative stress, gender, age, and length of stay among international college students in the United States. The findings from this study are intended to expand the existing literature on IA of international college students and its correlating factors.

\section{BACKGROUND}

IA was first proposed by Young (1998) and referred to as problematic Internet use, computer addiction, Internet use disorder, or excessive Internet use (Caplan, 2002; Van Rooij \& Prause, 2014; Young, 1996). Conceptualizations of IA have adhered to two distinct explanations: (a) it is a broad term that covers a wide variety of behavioral and impulse-control problems (Young, 1999), and (b) "many of these excessive users are not 'Internet addicts' but just use the Internet excessively as a medium to fuel other addictions" (Griffiths, 2000, p. 416). Although IA has not been included in the spectrum of addictive disorders in the Diagnostic and Statistical Manual of Mental Disorders, Fifth Edition (DSM-5) or the International Classification of Diseases Tenth Edition (ICD-10), concern is rapidly increasing with respect to its risk factors (Choi et al., 2015; Hyun et al., 2015). For example, research has identified several risk factors that are closely related to IA of college students, including psychological well-being (e.g., stress and loneliness; Ostovar et al., 2016), social contexts (e.g., lack of family support, poor academic performance; Cheng \& Hong, 2017; Jun \& Choi, 2015), coping strategies (Chou et al., 2015), and personal habits (e.g., poor control of Internet use; Lam, 2014). These risk factors are often presented individually, coexist and interact with one another, and increase the likelihood of getting college students addicted to the Internet (Choi et al., 2015). 


\section{International College Students}

Over the last years (2009-2010 to 2019-2020), the number of international students seeking degrees in the United States has increased substantially, from nearly 202,970 to 267,712 (Institute of International Education, 2020). The transition to college life, and to a potentially more diverse and more multicultural environment on the university campus, always brings new demands and challenges to international students (Ruberman, 2014). These demands and challenges are especially acute for racial and cultural minority international students from Asian countries (Ching et al., 2017). For example, Sherry et al. (2010) found that Asian international students often feel culturally misunderstood and socially isolated in the university community. These students appear to be more at risk of addiction during this process of cultural change (Blanco et al., 2008; Lonner et al., 2007). In an investigation of 110 Chinese international students studying in Korea, Kim et al. (2015) found that $40 \%$ of their participants were at-risk smartphone users; smartphone addiction may also have an adverse impact on physical health in the process of cross-cultural adaptation.

\section{Acculturative Stress}

The transition to the university environment often creates considerable stress in the lives of students and shapes how they perceive and respond to these kinds of life changes in the future (Besser \& Zeigler-Hill, 2014). In this study, I refer to acculturative stress as the stress associated with adjustment to a different culture and "a response by people to life events that are rooted in intercultural contact" (Berry, 2005, p. 43). This term includes two major theoretical perspectives: (a) psychological difficulty associated with cultural contact (e.g., from African American neighborhoods to low-diversity, White-dominant neighborhoods; or from Eastern cultures to Western cultures), or how individuals handle negative, stressful experiences during their adaption to the new environment; and (b) the sources of the negative experiences (e.g., perceived discrimination, loneliness) existing in the interaction between cultures (Bachman et al., 2011; Brown \& Aktas, 2011; Lazarus \& Folkman, 1984). According to Berry (2005), acculturative stress is a phenomenon that may have a negative impact on the health of individuals.

Research has noted several factors associated with acculturative stress. The most salient of these factors include gender (Livingston et al., 2007), ethnic identity (Walker et al., 2008), racial identity (Thompson et al., 2000), language proficiency ( $\mathrm{Li}$ et al., 2016), perceived discrimination (Utsey et al., 2000), homesickness (Poyrazli \& Lopez, 2007), hate and rejection (Henson et al., 2013; Schmitt et al., 2003), fear (Brown \& Aktas, 2011; Chao et al., 2014), social support (Ra \& Trusty, 2016), and cultural shock (Lombard, 2014; Torres, 2009; Winkelman, 1994). Moreover, longitudinal studies have indicated that acculturative stress is positively associated with depression (Du et al., 2015), homesickness (Tartakovsky, 2007), and substance abuse (Lorenzo-Blanco \& Unger, 2015) among international students and immigrants. Likewise, Jin and 
Berge (2016) reported that an individual's levels of acculturative stress predict their levels of IA. In the investigation of 115 East Asian international students in the United States, Ye (2005) found that acculturative stress is associated with motives for Internet use. For example, fear and perceived discrimination are significant predictors of social utility motivation among international students (Ye, 2005).

\section{Purpose of the Present Study}

International college students represent a group that could be more prone to IA because they are using the Internet at high rates (Doring et al., 2015). The transition to a culturally different college life might become a major turning point that affects international college students' habit of Internet use, making them more vulnerable to IA. In addition, prior research has primarily focused on homogeneity in effect sizes of IA among college students but is limited by a lack of racially and culturally diverse samples, or without considering acculturative stress.

In this pilot study, we therefore explored the relationship between acculturative stress, gender, age, length of stay, and IA in a sample of international college students using a multiple regression model. Specially, we were interested in the associations of acculturative stress with IA. Previous studies have shown that acculturative stress has been widely linked to addictive behaviors and psychological well-being among international college students (Conn et al., 2017; Jin \& Berge, 2015; Li et al., 2013). Thus, I hypothesized that acculturative stress would significantly predict IA while individual-level variables (i.e., age, gender, and length of stay) were held constant.

\section{METHOD}

\section{Participants}

A random sample of 300 international college students was invited to participate in a web-based survey that took 15-20 min to complete. These participants first reviewed the informed consent approved by the university's institutional review board. As part of the consent form, participants were informed that they could also stop participating at any time and that choosing to discontinue participating would not affect their academic performance. Of 111 responses, 93 fully completed the survey and were included in my final data analysis. Therefore, I received a $31 \%$ response rate.

Of the 93 participants, $63(67.7 \%)$ were male, $28(30.1 \%)$ were female, and two $(2.2 \%)$ were unidentified. Ages ranged from 22 to 40 years old $(M=28.62$, $S D=3.69)$. Regarding race/ethnicity, eight $(8.6 \%)$ were Caucasian, five $(5.4 \%)$ were African American, 63 (67.7\%) were Asian, and 12 (12.9\%) were biracial. Thirty-eight (40.9\%) were undergraduate and 55 (59.1\%) were master's students. Participants were from 27 countries. The top three countries were India $(n=21)$, China $(n=9)$, and Sri Lanka $(n=6)$. 


\section{Procedure}

Institutional review board approval was obtained prior to beginning the study. Participants were international students pursuing baccalaureate or graduate degrees in a large Midwestern research institution in the United States. I selected participants for the current study on the basis of specific criteria: (a) current enrollment in the target university; (b) possession of a valid student visa; (c) literate in English; and (d) between the ages of 18 and 70 years. Participants were recruited through a university research laboratory. A convenience sample was used based on who voluntarily responded. The research laboratory sent a recruitment email to 300 students studying in the university. The email included a brief introduction to the study as well as an anonymous link, which took potential participants to an online survey portal in Qualtrics. After participants provided online assent, they responded to the survey questions, which consisted of the IA test, acculturative stress questionnaire, and a brief demographic questionnaire. Two reminder emails were sent at 2-week intervals to those who had not yet completed the survey. An incentive, four \$25 Amazon gift cards, was offered with 1:75 odds.

\section{Measures}

\section{Demographic Questionnaire}

I developed a demographic questionnaire for this study using the tailored design method (Dillman et al., 2014). Participants were asked to self-report their racial and ethnic background, birthplace, age, gender, length of time in the United States, and educational history.

\section{Internet Addiction Test}

The Internet Addiction Test (IAT; Young, 1998) is a 20-item scale that measures the presence and severity of Internet dependency among adults. The IAT views IA as an impulse-control disorder and the term Internet refers to all types of online activity (Young, 1998). The 20-item questionnaire measures characteristics and behaviors associated with use of the Internet that include compulsivity, escapism, and dependency. Questions also assess problems related to addictive use in personal, occupational, and social functioning. Questions are randomized, and each statement is weighted along a Likert-scale continuum that ranges from 0 (less extreme behavior) to 5 (most extreme behavior) for each item.

Studies have found that the IAT is a reliable measure that covers the key characteristics of problematic Internet use (Boysan et al., 2017; Young, 1998). The assessment measures the extent of a respondent's involvement with the Internet and classifies the addictive behavior in terms of mild, moderate, or severe impairment. The IAT is a worldwide accepted and validated testing instrument and is the most widely used IA scale. The test has been translated into several languages including English, Chinese, French, Italian, Turkish, and Korean. 
Cronbach's alpha coefficient was .93 in Noh and Kim's study (2016) and .91 in the current study, showing that the IAT is highly reliable.

\section{Acculturative Stress Scale}

Acculturative stress was assessed with the 36-item Acculturative Stress Scale for International Students (ASSIS; Sandhu \& Asrabadi, 1994). Items were rated on a 5-point Likert-type scale from 1 (strongly disagree) to 5 (strongly agree), with higher scores indicating greater level of acculturative stress, such as "I feel that my people are discriminated against" or "I am treated differently because of my color." It consisted of seven subscales, including perceived discrimination (eight items), homesickness (four items), perceived hate/rejection (five items), fear (four items), stress due to change/culture shock (three items), guilt (two items), and nonspecific concerns (10 items). For this study, five nonspecific concerns were taken from the ASSIS scale. Several studies reported high internal consistency reliability of the ASSIS ranging from .87 to .93 (Bai, 2016; Constantine et al., 2004). Internal consistency reliabilities in this sample were as follows: total scale: .91; perceived discrimination, .83; homesickness, .75; perceived hate, .84; fear, .83; culture shock, .59; guilt, .66; and nonspecific concerns, .61.

\section{Data Analysis}

I conducted a preliminary analysis to determine whether a relationship existed between age, gender, length of stay, and acculturative stress. The presence of a relationship would warrant further exploration of the relationship between IA and acculturative stress. I assessed normality across study variables by examining skewness, kurtosis, and quantile-quantile plots. According to George and Mallery (2005), skewness and kurtosis for all predictor variables fell within normal ranges $(-1$ to +1$)$. Therefore, I determined no transformation of the data was needed. No apparent multicollinearity issues occurred among predictor variables. Several instances of missing or discrepant data found on the demographic questionnaire were addressed by using pairwise deletion.

\section{RESULTS}

I used SPSS (Version 24) to conduct statistical analyses. I conducted multiple regression analyses to examine how the individual-level variables (age, gender, length of stay) and seven subscales of the acculturative stress (discrimination, homesickness, hate, fear, cultural shock, guilt, and nonspecific concerns) predicted IA among international college students. Table 1 summarizes the descriptive statistics of the acculturative stress and IA. 
Table 1: Descriptive Statistics of Acculturative Stress and Internet Addiction

\begin{tabular}{lcccc}
\hline & Min & Max & $M$ & $S D$ \\
\hline Internet addiction & 22 & 80 & 37.82 & 12.93 \\
Discrimination & 8 & 35 & 20.95 & 6.38 \\
Homesickness & 4 & 20 & 10.96 & 3.50 \\
Hate & 5 & 22 & 10.72 & 4.19 \\
Fear & 4 & 18 & 8.58 & 3.72 \\
Cultural Shock & 3 & 15 & 7.65 & 2.87 \\
Guilt & 2 & 10 & 4.63 & 2.17 \\
Nonspecific & 5 & 21 & 13.84 & 4.04 \\
\hline
\end{tabular}

To address our hypothesis, two clusters of variables were entered sequentially to complete hierarchical multiple regression analyses. First, individual-level variables (age, gender, and length of stay) were included in Model 1, explaining $42.9 \%$ of variance in IA, F $(3,66)=4.97, p=.004$. Second, in Model 2, seven subscales of the acculturative stress were added into Model 1. The total variance in Model 2 was $58.6 \%, F(10,59)=3.09, p=.003$. The seven subscales explained an additional $15.7 \%$ of the variance in Model 2, after controlling age, gender, and length of stay.

Table 2: Generalized Linear Modeling Predicting Internet Addiction

\begin{tabular}{lcc}
\hline Predictors & Model $1(\beta)$ & Model 2 $(\beta)$ \\
\hline Age & -.17 & -.22 \\
Gender & $.39 * *$ & $.33^{* *}$ \\
Length of stay & .18 & .20 \\
Discrimination & & -.07 \\
Homesick & & .03 \\
Hate & & .16 \\
Fear & & .14 \\
Cultural shock & .18 & $.34^{*}$ \\
Guilt & .03 \\
Nonspecific concerns & & -.18 \\
$R^{2}$ & & .34 \\
\hline
\end{tabular}

Note. ${ }^{*} p<.05, * * p<.01 ; * * * p<.001$

As can be seen in Table 2, gender is the variable significantly predicting IA in both Models 1 and 2. Male students apparently were more likely than female students to show symptoms of IA. Model 2 indicates that only cultural shock ( $\beta$ $=.34, p=.02$ ) significantly predicted IA, after controlling for the individual-level variables. Therefore, our hypothesis was supported.

\section{DISCUSSION}

The main purpose of this study was to investigate acculturative stress in relation to IA among a random sample of international college students studying in a large 
Midwestern research institution in the United States. Given the acculturative stress theory provided by Berry $(1977,2005)$, which postulates that contextual factors impact the level of acculturative stress, this study yields a few important findings about the relationships between acculturative stress and IA in a diverse college student sample. Notably, acculturative stress was a statistically significant variable in Model 2 and may be a warning sign for international college students who might use the Internet to meet their cultural and social-emotional needs while moving from a familiar culture to one that is unfamiliar. Our findings are consistent with a large body of research suggesting that perceived discrimination, homesickness, and cultural shock are still prevalent in international students living in the United States (Chai et al., 2012; Chao et al., 2014; Henson et al., 2013; Li et al., 2013; Poyrazli \& Lopez, 2007), and that acculturative stress in particular plays a significant role in contributing to mental health (Ran et al., 2016; Thompson et al., 2000; Torres et al., 2012). Thus, student service personnel and college counselors need to be concerned with psychological changes of international students who have experienced discrimination and cultural shock. Universities should deliver culturally responsive education to this population and help them deal with stress associated with race- and culture-based discrimination.

Acculturative stress, including its subscales such as cultural shock, may be considered as a predictor of IA in our study. Our finding might be regarded as an extension of previous studies in the literature regarding perceived stress that is related to addictive behaviors (Cheng \& Hong, 2017; Gil et al., 2015; Sinha \& Jastreoboff, 2013). The similarity of the findings may be explained by the prevalence of the sense of insecurity and the stress associated with acculturation in unfamiliar surroundings among international college students. However, although literature has indicated there might be a possible causal relationship between these psychological symptoms (i.e., stress) and IA, some scholars argue that this association needs further investigation (Ostovar et al., 2016). Our results assume that international college students become addicted to the Internet as a means of relieving their psychological distress caused by life changes. Thus, a culturally responsive counselor should begin with examining recent life experience and coping strategies of college students before addressing their addictive problems.

Another significant finding of the present study was that gender moderated the relationship between acculturative stress and IA. This finding is consistent with previous research (Khan et al., 2017; Livingston et al., 2007) and Berry's acculturative stress theory $(1997,2005)$, which indicate that gender is a significant moderating factor for acculturative stress (Berry, 1977, 2005; Dawson \& Panchanadeswaran, 2010). Our finding is also in line with previous studies examining the effect of gender difference on problematic Internet use (Gupta et al., 2018; Ioannidis et al., 2018). In particular, male students apparently show a higher level of IA than female students when they are of a similar age. The current study highlights the need for researchers and college counselors to thoroughly weigh the gender factor in terms of international students' vulnerability to IA. Given that much research has focused on cause, diagnosis, and treatment of IA in college students, additional research is needed that incorporates a more nuanced 
view of these demographic factors (e.g., marital status, ethnicity/racial identity, socioeconomic status) for IA in international college student populations.

\section{Limitations and Future Research}

Although our findings contribute to the acculturative stress and IA research pertaining to international college students, several limitations must be considered. First, although expected, these small sample sizes may have resulted in statistical power being lower than desired. Future research could pool a larger sample to examine relationships between IA and acculturative stress among international college students. Second, because of the lack of prior research on acculturative stress and IA, we developed our research questions based on the available acculturation research (Chai et al., 2012; Chao et al., 2014; Henson et al., 2013; Li et al., 2013; Poyrazli \& Lopez, 2007). Some other important variables (e.g., acculturation strategies, personality) potentially should have been included in our study. In addition, we tested individual-level variables (e.g., gender, age, length of stay) in the current study and future researchers could supply knowledge on acculturative stress and IA by exploring moderating factors of acculturation (e.g., social support, societal attitudes, coping strategies) as well as additional demographic factors (e.g., socioeconomic status, racial/ethnicity identity, marital status). Third, the measures used in the web-based survey were not mandatory, which may account for the incompleteness.

\section{Implications for College Counselors}

This study was innovative in examining the influence of acculturative stress on IA among international college students. Two key findings from this study were that (a) acculturative stress has a positive influence on IA; and (b) gender and cultural shock may have unique contributions to IA among international college students. With the established research linking acculturative stress and IA, some clinical implications for college counselors emerge from this study. College counselors should consider how acculturative stress might be exacerbating addictive Internet use. Previous research linking multicultural counseling competences suggests that (a) multicultural counselors should be aware of self, client, and potential barriers in the counseling process when working with international and minority students; (b) discussions with students around confidentiality should be initiated beforehand to help ward off fear or culturerelated stress that may occur, particularly when working with international students; and (c) college counselors should focus on a more directive approach to counseling this population (Mau \& Jepsen, 1988; Yau et al., 1992; Yakunina et al., 2013). Likewise, when dealing with international students who are addicted to the Internet, college counselors are encouraged to review contemporary literature regarding IA associated with different psychological symptoms. As the findings reported, cultural sensitivity should be used to interpret perceived discrimination, homesickness, hate, and cultural shock and empathy should be shown for students from diverse cultural backgrounds. A college counselor should 
pay particular attention to these issues that may lead to unintended harm on students.

\section{CONCLUSION}

Given the prevalence of IA in U.S. colleges and universities, the factors that contribute to this addictive behavior are increasingly important to understand. Using acculturative stress theory that accounts for a sociocultural transition and examining moderating factors that influence the transition can help college counselors understand needs of international students. Furthermore, the findings from this study also shift our current understanding of the relationship between acculturative stress and IA. Male students' higher acculturative stress apparently has a significant influence on IA. Hopefully, this study contributes to the growing literature on IA from a perspective of cultural transition. Findings from this study also present additional research questions that warrant further consideration in future research.

\section{REFERENCES}

Anderson, K. (2001). Internet use among college students: An exploratory study. Journal of American College Health, 50, 21-26. doi:10.1080/07448480109595707

Bachman, R., Randolph, A., \& Brown, B. L. (2011). Predicting perceptions of fear at school and going to and from school for African American and White students: The effects of school security measures. Youth \& Society, 43, 705726. doi:10.1177/0044118X10366674

Bai, J. (2016). Development and validation of the Acculturative Stress Scale for Chinese college students in the United States (ASSCS). Psychological Assessment, 28, 443-447. doi:10.1037/pas0000198

Berry, J. W. (1977). Immigration, acculturation, and adaptation. Applied Psychology: An International Review, 46, 5-34. doi:10.111/j.14640597.1977.tb01087.x

Berry, J. W. (2005). Acculturation: Living successfully in two cultures. International Journal of Intercultural Relations, 29, 697-712. doi:10.1016/j.ijintrel.2005.07.013

Besser, A., \& Zeigler-Hill, V. (2014). Positive personality features and stress among first-year university students: Implications for psychological distress, functional impairment, and self-esteem. Self \& Identity, 13, 24-44. doi:10.1080/15298868.2012.736690.

Blanco, C., Okuda, M., Wright, C., Hasin, D. S., Grant, B. F., Liu, S.-M., \& Olfson, M. (2008). Mental health of college students and their non-collegeattending peers: Results from the national epidemiologic study on alcohol and related conditions. Archives of General Psychiatry, 65, 1429-1437. doi:10.1001/archpsyc.65.12.1429 
Boysan, M., Kuss, D. J., Barut, Y., Ayköse N., Güleç, M., \& Özdemir, O. (2017). Psychometric properties of the Turkish version of the Internet Addiction Test (IAT). Addictive Behaviors, 64, 247-252. doi:10.1016/j.addbeh.2015.09.002

Brown, L., \& Aktas, G. (2011). Fear of the unknown: A pre-departure qualitative study of Turkish international students. British Journal of Guidance \& Counselling, 39, 339-355. doi:10.1080/03069885.2011.576314

Caplan, S. E. (2002). Problematic Internet use and psychosocial well-being: Development of a theory-based cognitive-behavioral measurement instrument. Computers in Human Behavior, 18, 553-575. doi:10.1016/S0747-5632(02)00004-3

Cardak, M. (2013). Psychological well-being and Internet addiction among university students. Turkish Online Journal of Educational Technology TOJET, 12(3), 134-141.

Carlisle, K. L., Carlisle, R. M., Polychronopoulos, G. B., Goodman-Scott, E., \& Kirk-Jenkins, A. (2016). Exploring Internet addiction as a process addiction. Journal of Mental Health Counseling, 38, 170-182. doi: $10.17744 /$ mehc.38.2.07

Chai, P. M., Krägeloh, C. U., Shepherd, D., \& Billington, R. (2012). Stress and quality of life in international and domestic university students: Cultural differences in the use of religious coping. Mental Health, Religion \& Culture, 15, 265-277. doi:10.1080/13674676.2011.571665

Chao, R. C., Longo, J., Wang, C., Dasgupta, D., \& Fear, J. (2014). Perceived racism as moderator between self-esteem/shyness and psychological distress among African Americans. Journal of Counseling \& Development, 92, 259269. doi:10.1002/j.1556-6676.2014.00154.x

Cheng, K. T., \& Hong, F. Y. (2017). Study on relationship among university students' life stress, smart mobile phone addiction, and life satisfaction. Journal of Adult Development, 24, 109-118. doi:10.1007/s10804-016-92509

Ching, Y., Renes, S. L., McMurrow, S., Simpson, J., \& Strange, A. T. (2017). Challenges facing Chinese international students studying in the United States. Educational Research and Reviews, 12, 473-482. doi: $10.5897 /$ err2016.3106

Choi, S. W., Kim, D. J., Choi, J. S., Ahn, H., Choi, E. J., Song, W. Y., \& Youn, H. (2015). Comparison of risk and protective factors associated with smartphone addiction and Internet addiction. Journal of Behavioral Addictions, 4, 308-314. doi:10.1556/2006.4.2015.043

Chou, W., Ko, C., Kaufman, E. A., Crowell, S. E., Hsiao, R. C., Wang, P. W., Lin, J., \& Yen, C. F. (2015). Association of stress coping strategies with Internet addiction in college students: The moderating effect of depression. Comprehensive Psychiatry, 62, 27-33. doi:10.1016/j.comppsych.2015.06.004

Conn, B. M., Ejesi, K., \& Foster, D. W. (2017). Acculturative stress as a moderator of the effect of drinking motives on alcohol use and problems among young adults. Addictive Behaviors, 75, 85-94. doi:10.1016/j.addbeh.2017.06.017 
Constantine, M. G., Okazaki, S., \& Utsey, S. O. (2004). Self-concealment, social self-efficacy, acculturative stress, and depression in African, Asian, and Latin American international college students. American Journal of Orthopsychiatry, 74, 230-241. doi:10.1037/0002-9432.74.3.230

Dawson, B. A., \& Panchanadeswaran, S. (2010). Discrimination and acculturative stress among first-generation Dominicans. Hispanic Journal of Behavioral Sciences, 32, 216-231 doi:10.1177/0739986310364750

Dillman, D. A., Smyth, J. D., \& Christian, L. M. (2014). Internet, phone, mail, and mixed-mode surveys: The tailored design method (4th ed.). Wiley.

Doring, N., Daneback, K., Shaughnessy, K., Grov, C., \& Byers, E. S. (2015). Online sexual activity experience among college students: A four-country comparison. Archives of Sexual Behavior, 46, 1641-1652. doi:10.1007/s10508-015-0656-4

Du, H., Li, X., Lin, D., \& Tam, C. (2015). Collectivistic orientation, acculturative stress, cultural self-efficacy, and depression: A longitudinal study among Chinese internal migrants. Community Mental Health Journal, 51(2), 239248. doi:10.1007/s10597-014-9785-9

Gaille, B. (2017, May 22). 33 interesting Internet addiction statistics. $\mathrm{http} / / /$ brandongaille.com/32-interesting-internet-addiction-statistics/

George, D., \& Mallery, P. (2005). SPSS for Windows: Step by step (5th ed.). Pearson.

Gil, F., Chamarro, A., \& Oberst, U. (2015). Addiction to online social networks: A question of "Fear of Missing Out"? Journal of Behavioral Addictions, 4(S1), 51. doi:10.1556/JBA.4.2015.Suppl.1

Gregory, C. (May 22, 2019). Internet addiction disorder. PSYCOM. https://www.psycom.net/iadcriteria.html

Griffiths, M. (2000). Internet addiction-Time to be taken seriously? Addiction Research, 8(5), 413-418. doi:10.3109/16066350009005587

Gupta, A., Khan, A. M., Rajoura, O. P., \& Srivastava, S. (2018). Internet addiction and its mental health correlates among undergraduate college students of a university in north India. Journal of Family Medicine and Primary Care, 7(4), 721-727. doi:10.4103/jfmpc.jfmpc_266_17

Henson, J. M., Derlega, V. J., Pearson, M. R., Ferrer, R., \& Holmes, K. (2013). African American students' responses to racial discrimination: How racebased rejection sensitivity and social constraints are related to psychological reactions. Journal of Social \& Clinical Psychology, 32, 504-529. doi:10.1521/jscp.2013.32.5.504

Hirai, R., Frazier, P., \& Syed, M. (2015). Psychological and sociocultural adjustment of first-year international students: Trajectories and predictors. Journal of Counseling Psychology, 62, 438-452. doi:10.1037/cou0000085

Hyun, G. J., Han, D. H., Lee, Y. S., Kang, K. D., Yoo, S. K., Chung, U., \& Renshaw, P. F. (2015). Risk factors associated with online game addiction: A hierarchical model. Computers in Human Behavior, 48, 706-713. doi:10.1016/j.chb.2015.02.008

Ineme, M. E., Ineme, K. M., Akpabio, G. A., \& Osinowo, H. O. (2017). Predictive roles of depression and demographic factors in Internet addiction: A cross- 
sectional study of students in a Nigerian university. International Journal of Cyber Criminology, 11, 10-23. doi:10.5281/zenodo.495776

Institute of International Education. (2020). New International Student Enrollment. https://opendoorsdata.org/data/international-students/newinternational-students-enrollment/

Ioannidis, K., Treder, M. S., Chamberlain, S. R., Kiraly, F., Redden, S. A., Stein, D. J., Grant, J. E. (2018). Problematic internet use as an age-related multifaceted problem: Evidence from a two-site survey. Addictive Behaviors, 81, 157-166. doi:10.1016/j.addbeh.2018.02.017

Jin, S. W., \& Berge, J. (2015). An emerging global concern of Internet addiction: Socio-cultural influences on immigrant families. Global Studies Journal, 9(1), 15-34.

Jun, S., \& Choi, E. (2015). Academic stress and Internet addiction from general strain theory framework. Computers in Human Behavior, 49, 282-287. doi:10.1016/j.chb.2015.03.001

Kandell, J. J. (2009). Internet addiction on campus: The vulnerability of college students. CyberPsychology \& Behavior, 1, 11-17. doi:10.1089/cpb.1998.1.11

Khan, M. A., Shabbir, F., \& Rajput, T. A. (2017). Effect of gender and physical activity on Internet addiction in medical students. Pakistan Journal of Medical Sciences, 33, 191-94. doi:10.12669/pjms.331.11222

Kim, S., Kim, J., \& Jee, Y. (2015). Relationship between smartphone addiction and physical activity in Chinese international students in Korea. Journal of Behavioral Addiction, 4. http://dx.doi.org/10.1556/2006.4.2015.028

Lam, L. T. (2014). Risk factors of Internet addiction and the health effect of Internet addiction on adolescents: A systematic review of longitudinal and prospective studies. Current Psychiatry Reports, 16(11), 508-516. doi:10.1007/s11920-014-0508-2

Lazarus, R. S., \& Folkman, S. (1984). Stress, appraisal and coping. Springer.

Li, J., Liu, X., Wei, T., \& Lan, W. (2013). Acculturation, Internet use, and psychological well-being among Chinese international students. Journal of International Students, 3(2), 174-192.

Li, J., Marbley, A. F., Bradley, L., \& Lan, W. (2016). Attitudes toward seeking counseling services among Chinese international students: Acculturation, ethnic identity, and language proficiency. Journal of Multicultural Counseling and Development, 44, 65-76. doi:10.1002/jmcd.12037

Livingston, I. L., Neita, M., Riviere, L., \& Livingston, S. L. (2007). Gender, acculturative stress and Caribbean immigrants' health in the United States of America-An exploratory study. The West Indian Medical Journal, 56, 213222. doi:10.1590/s0043-31442007000300004

Lombard, C. A. (2014). Coping with anxiety and rebuilding identity: A psychosynthesis approach to culture shock. Counselling Psychology Quarterly, 27, 174-199. doi:10.1080/09515070.2013.875887

Lonner, W., Wong, P. T., \& Wong, L. C. (2007). Handbook of multicultural perspectives on stress and coping. Springer Science \& Business Media. 
Lorenzo-Blanco, E., \& Unger, J. U. (2015). Ethnic discrimination, acculturative stress, and family conflict as predictors of depressive symptoms and cigarette smoking among Latina/o youth: The mediating role of perceived stress. Journal of Youth \& Adolescence, 44, 84-97. doi:10.1007/s10964-015-03394

Mau, W. C., \& Jepsen, D. A. (1988). Attitudes toward counselors and counseling processes: A comparison of Chinese and American graduate students. Journal of Counseling and Development, 67, 189-192.

Noh, D., \& Kim, S. (2016). Dysfunctional attitude mediates the relationship between psychopathology and Internet addiction among Korean college students: A cross-sectional observational study. International Journal of Mental Health Nursing, 25, 588-597. doi:10.1111/inm.12220

Ostovar, S., Allahyar, N., Aminpoor, H., Moafian, F., Nor, M. M., \& Griffiths, M. D. (2016). Internet addiction and its psychosocial risks (depression, anxiety, stress and loneliness) among Iranian adolescents and young adults: A structural equation model in a cross-sectional study. International Journal of Mental Health and Addiction, 14, 257-267. doi:10.1007/s11469-0159628-0

Poyrazli, S., \& Lopez, M. D. (2007). An exploratory study of perceived discrimination and homesickness: A comparison of international students and American students. Journal of Psychology, 141, 263-280. doi:10.3200/JRLP.141.3.263-280

Ra, Y. A., \& Trusty, J. (2017). Impact of social support and coping on acculturation and acculturative stress of East Asian international students. Journal of Multicultural Counseling and Development, 45, 276-291. doi:10.1002/jmcd.12078

Ruberman, L. I. (2014). Challenges in the transition to college: The perspective of the therapist back home. American Journal of Psychotherapy, 68(1), 103115 .

Sandhu, D. S., \& Asrabadi, B. R. (1994). Development of an acculturative stress scale for international students: Preliminary findings. Psychological Reports, 75, 435-448. doi:10.2466/pr0.1994.75.1.435

Schmitt, M. T., Spears, R., \& Branscombe, N. R. (2003). Constructing a minority group identity out of shared rejection: The case of international students. European Journal of Social Psychology, 33, 1-12. doi:10.1002/ejsp.131

Sherry, M., Thomas, P., \& Chui, W. (2010). International students: A vulnerable student population. Higher Education, 60, 33-46. doi:10.1007/s10734-0099284-Z

Sinha, R., \& Jastreboff, A. M. (2013). Stress as a common risk factor for obesity and addiction. Biological Psychiatry, 73, 827-835. doi:10.1016/j.biopsych.2013.01.032

Tartakovsky, E. (2007). A longitudinal study of acculturative stress and homesickness: High-school adolescents immigrating from Russia and Ukraine to Israel without parents. Social Psychiatry \& Psychiatric Epidemiology, 42, 485-494. doi:10.1007/s00127-007-0184-1 
Thompson, C. P., Anderson, L. P., \& Bakeman, R. A. (2000). Effects of racial socialization and racial identity on acculturative stress in African American college students. Cultural Diversity and Ethnic Minority Psychology, 6, 196210. doi:10.1037/1099-9809.6.2.196

Torres, K. (2009). 'Culture shock': Black students account for their distinctiveness at an elite college. Ethnic \& Racial Studies, 32(5), 883-905. doi:10.1080/01419870701710914

Torres, L., Driscoll, M. W., \& Voell, M. (2012). Discrimination, acculturation, acculturative stress, and Latino psychological distress: A moderated mediational model. Cultural Diversity and Ethnic Minority Psychology, 18, 17-25. doi:10.1037/a0026710

Utsey, S. O., Ponterotto, J. G., Reynolds, A. L., \& Cancelli, A. A. (2000). Racial discrimination, coping, life satisfaction, and self-esteem among African Americans. Journal of Counseling \& Development, 78, 72-80. doi:10.1002/j.1556-6676.2000.tb02562.x

Van Rooij, A. J., \& Prause, N. (2014). A critical review of "Internet addiction" criteria with suggestions for the future. Journal of Behavioral Addictions, 3(4), 203-213. doi:10.1556/JBA.3.2014.4.1

Walker, R. L., Wingate, L. R., Obasi, E. M., \& Joiner, T. E. (2008). An empirical investigation of acculturative stress and ethnic identity as moderators for depression and suicidal ideation in college students. Cultural Diversity and Ethnic Minority Psychology, 14, 75-82. doi:10.1037/1099-9809.14.1.75

Weinstein, A., \& Lejoyeux, M. (2010). Internet addiction or excessive internet use. The American Journal of Drug and Alcohol Abuse, 36(5), 277-283. doi: $10.3109 / 00952990.2010 .491880$

Winkelman, M. (1994). Cultural shock and adaptation. Journal of Counseling \& Development, 73, 121-126. doi:10.1002/j.1556-6676.1994.tb01723.x

Yakunina, E. S., Weigold, I. K., Weigold, A., Hercegovac, S., \& Elsayed, N. (2013). International students' personal and multicultural strengths: Reducing acculturative stress and promoting adjustment. Journal of Counseling \& Development, 91(2), 216-223. doi:10.1002/j.15566676.2013.00088.x

Yau, T. Y., Sue, D., \& Hayden, D. (1992). Counseling style preference of international students. Journal of Counseling Psychology, 39, 100-104. doi:10.1037/0022-0167.39.1.100

Ye, J. (2005). Acculturative stress and use of the Internet among East Asian international students in the United States. Cyberpsychology \& Behavior, 8, 154-161. doi:10.1089/cpb.2005.8.154

Young, K. S. (1996, August). Internet addiction: The emergence of a new clinical disorder [Paper presentation]. 104th Annual Meeting of the American Psychological Association, Toronto, Ontario, Canada.

Young, K. S. (1998). Internet addiction: The emergence of a new clinical disorder. CyberPsychology \& Behavior, 1(3), 237-244. doi:10.1089/cpb.1998.1.237

Young, K. S. (1999). Internet addiction: Symptoms, evaluation, and treatment. In L. Vande Creekve \& T. Jackson (Eds.), Innovations in clinical practice: A source book (pp. 19-31). Professional Resources Press. 
Zeliha, T. (2019). Internet addiction and loneliness as predictors of Internet gaming disorder in adolescents. Educational Research and Review, 14, 465473. doi:10.5897/err2019.3768

JIAQI (JASON) LI, PhD, is an associate professor in the Department of Counseling, Educational Leadership, Educational and School Psychology in the College of Applied Studies at Wichita State University. He received his PhD in Counselor Education and Supervision at Texas Tech University. His research interests are broadly in the areas of career development, addictive behaviors, and mental issues of underrepresented groups in the school setting. He is a licensed professional counselor and national certified counselor in the state of Kansas. Email: Jason.li@wichita.edu

XUN LIU, PhD, is Independent Methodologist in the Consortium for Family Strengthening Research in the College of Education at University of South Carolina. Her research interests focus on quantitative research methodology, marriage and family studies, scale development and measurement. Email: xuntwoxun@gmail.com 